\title{
Long-Term Survival of Patients Receiving Artificial Nutrition in Japanese Psychiatric Hospitals
}

\author{
Keiichi Abe $^{a}$ Ryuko Yamashita ${ }^{b} \quad K^{2}$ eiko Kondo ${ }^{g}$ Keiko Takayama ${ }^{\text {h }}$ \\ Osamu Yokota ${ }^{i}$ Yoshiki Sato $^{j}$ Mitsumasa Kawai Hideki Ishizu ${ }^{c}$

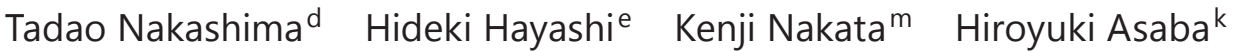 \\ Koichi Kadotan $^{n}$ Kazuyoshi Tanaka $^{p}$ Yumi Morisada ${ }^{\circ}$ Etsuko Oshima ${ }^{f}$ \\ Seishi Terada ${ }^{f}$ Middle Western Japan Dementia Study (mid-Dem study) \\ Departments of Psychiatry, a Mannari Hospital, b Kawada Hospital, ' Zikei Hospital, \\ d'Sanyo Hospital, and ${ }^{\mathrm{e} H a y a s h i}$ Hospital, and f Department of Neuropsychiatry, Okayama \\ University Graduate School of Medicine, Dentistry and Pharmaceutical Sciences, Okayama, \\ Departments of Psychiatry, ${ }^{9}$ Sekizen Hospital and hibogaoka Hospital, Tsuyama, \\ 'Department of Psychiatry, Kinoko Espoir Hospital, Kasaoka, Departments of Psychiatry, \\ jYura Hospital and KKohnan Hospital, Tamano, 'Department of Psychiatry, Setouchi Kinen \\ Hospital, Setouchi, mDepartment of Psychiatry, Taiyo Hills Hospital, Takahashi, Departments \\ of Psychiatry, ${ }^{\text {}}$ Kurashiki Jinpu Hospital and ${ }^{\circ}$ Kurashiki Shinkeika Hospital, Kurashiki, and \\ ${ }^{\mathrm{P}}$ Department of Psychiatry, Koyodai Hospital, Maniwa, Japan
}

\section{Key Words}

Artificial nutrition · Dementia $\cdot$ Long-term care $\cdot$ Long-term survival $\cdot$ Nasogastric tube $\cdot$ Nutrition · Percutaneous endoscopic gastrostomy $\cdot$ Schizophrenia

\section{Abstract}

Background/Aims: Most patients with dementia suffer from dysphagia in the terminal stage of the disease. In Japan, most elderly patients with dysphagia receive either tube feeding or total parenteral nutrition. Methods: In this study, we investigated the factors determining longer survival with artificial nutrition. Various clinical characteristics of 168 inpatients receiving artificial nutrition without oral intake in psychiatric hospitals in Okayama Prefecture, Japan, were evaluated. Results: Multiple logistic regression analysis showed that the duration of artificial nutrition was associated with a percutaneous endoscopic gastrostomy (PEG) tube, diagnosis of mental disorder, low MMSE score, and absence of decubitus. Conclusion: Patients with mental disorders survived longer than those with dementia diseases on artificial nutrition. A PEG tube and good nutrition seem to be important for long-term survival. 


\section{Introduction}

The aged population has increased in many developed countries including Japan. The frequency of dementia rises with advancing age. Therefore, the number of patients with dementia grows dramatically in many countries. Most patients with dementia suffer from dysphagia in the terminal stage of the disease. A recent systematic review reported that there was no evidence of longer survival of dementia patients receiving enteral tube feeding [1]. However, in many geriatric facilities worldwide, including Japan, clinical physicians continue to provide tube feeding to dementia patients for traditional, ethical, and administrative reasons [2, 3]. Especially in Japan, most elderly patients with dysphagia (about 90\%) receive either tube feeding or total parenteral nutrition (TPN) [4].

As stated above, several studies of the survival rate of dementia patients receiving percutaneous endoscopic gastrostomy (PEG) have shown that artificial nutrition by PEG tube feeding did not improve the prognosis of dementia patients compared to hand feeding [1, 5-7]. However, in those studies, there was no homogeneity in the dementia patients with and without PEG tube feeding. It is most likely that many patients without feeding tubes in those studies had better health [8] and that a so-called selection bias affected the results. Recently, some studies have shown that dementia patients with PEG tubes survived longer than those without $[2,4,8]$. Furthermore, it was also reported that dementia patients receiving PEG tube feeding survived as long as patients without dementia receiving PEG tube feeding [9-12]. In a recent report from Japan, 66\% of 931 consecutive dementia patients with PEG tube feeding survived over 1 year, and more than $50 \%$ of those patients survived over 2 years [3]. In another report, 74 patients (39.6\% of 187 patients) had been receiving artificial nutrition for more than 2 years and 28 patients (15.0\%) for more than 5 years [13].

Recently, several studies have reported factors affecting the duration of survival after PEG tube insertion. Younger age, female sex, higher albumin level, higher lymphocyte counts, and absence of cardiac failure were reported to predict longer survival among patients with a PEG tube [3, 9-11]. These studies did not include patients with psychiatric diseases. Currently, in Japan, not a few patients with psychiatric diseases suffer from dysphagia in the chronic stage and receive parenteral nutrition [13]. However, there have been no studies focusing on the factors affecting survival time after commencement of artificial nutrition, including in patients with mental diseases and patients receiving various methods of artificial nutrition. In this study, in order to determine the factors related to longer survival with artificial nutrition, we investigated the actual conditions of patients undergoing artificial nutrition by methods including nasogastric (NG) tube feeding, PEG tube feeding, and TPN in psychiatric hospitals in Okayama Prefecture, Japan.

\section{Subjects and Methods}

\section{Artificial Nutrition}

Artificial hydration and nutrition include enteral and intravenous nutrition. Enteral nutrition mainly consists of NG tube and PEG feeding, while intravenous nutrition comprises peripheral venous nutrition and TPN. Needless to say, peripheral venous nutrition cannot sustain human life for long. Therefore, only patients with a PEG tube, NG tube, or TPN and without oral intake were included in this study.

\section{Subjects}

This was a cross-sectional observational study. Almost all wards for dementia with behavioral and psychological symptoms of dementia are situated in psychiatric hospitals in 
Abe et al.: Long-Term Survival of Patients Receiving Artificial Nutrition in Japanese Psychiatric Hospitals

Japan. Due to the explosive increase in aged dementia patients, the number of care facilities for patients with dementia is not sufficient. Therefore, quite a few patients with dementia are cared for in many psychiatric hospitals even after behavioral and psychological symptoms of dementia have been well controlled.

We asked the Association of Okayama Psychiatry Hospitals to participate in the survey of inpatients undergoing artificial feeding. There are 20 psychiatric hospitals in Okayama Prefecture, and 18 of them agreed to participate in this survey. Inpatients receiving artificial nutrition for more than 1 month as of February 17, 2014, were included. All inpatients receiving artificial nutrition were evaluated in 16 of 18 hospitals. In 2 hospitals, 33 of 58 patients and 6 of 15 patients were investigated. Reasons for nonparticipation were heavy workload and/or shortage of personnel in the wards.

On February 17, 2014, there were 4,101 inpatients (2,094 women and 2,007 men) in 18 psychiatric hospitals of Okayama Prefecture. Of them, 221 patients (5.4\% of all inpatients) had been receiving artificial nutrition for more than 1 month. Of the 221 patients, 75 patients were male (3.7\% of all male inpatients) and 146 were female ( $7.0 \%$ of all female inpatients). Of 221 patients receiving continuous artificial nutrition, 187 patients (130 women and 57 men, $84.6 \%$ of 221 patients) were fully investigated. Of 187 patients, 168 patients (114 women and 54 men, $89.8 \%$ of 187 patients) received artificial nutrition without oral intake.

\section{Clinical Diagnosis}

All patients with Alzheimer's disease (AD) met the criteria for probable AD formulated by the NIA-AA [14]. AD patients with severe vascular lesions were diagnosed as possible AD with vascular lesions according to the criteria of the NIA-AA [14]. All patients with vascular dementia (VaD) were diagnosed according to the criteria for probable VaD of the AHA-ASA [15]. All patients with dementia with Lewy bodies (DLB) were diagnosed according to the criteria for probable DLB of the DLB Consortium [16]. All patients with frontotemporal dementia met the international consensus criteria for probable behavioral variant frontotemporal dementia [17]. Patients with schizophrenia fulfilled the International Classification of Diseases (ICD)-10 criteria for F2 codes, and patients with mood disorders fulfilled the ICD-10 criteria for F3 codes. Other disorders were diagnosed according to ICD-10 criteria.

\section{Questionnaires and Clinical Scales}

Clinical characteristics including age, clinical diagnosis, and duration and methods of artificial nutrition were investigated. The presence or absence of physical restraints and pressure ulcers at the time of the survey was included, and the number of cases of pneumonia in the previous year was also recorded.

The Functional Independence Measure (FIM) is a widely used functional assessment tool [18]. The FIM contains 18 items (13 motor tasks and 5 cognitive tasks). Each item is objectively rated on a 7-point scale, and a lower score indicates more severe impairment. The MiniMental State Examination (MMSE) is a screening test that has been used widely to evaluate the cognitive state [19]. The total score of the MMSE ranges from 0 to 30. A lower score indicates more severe impairment.

\section{Respondents}

Questionnaires were completed for all subjects by trained nurses or geriatric psychiatrists who were well acquainted with and chiefly in charge of the participants being rated. All raters had daily contact with the individuals being studied. The MMSE was evaluated by geriatric psychiatrists, clinical psychologists, or trained occupational therapists. 
Abe et al.: Long-Term Survival of Patients Receiving Artificial Nutrition in Japanese Psychiatric Hospitals

\section{Statistics}

Statistical analyses were performed using PASW Statistics 18.0 (SPSS, Chicago, Ill., USA). The comparison between the three groups was made using one-way analysis of variance (ANOVA), followed by Tukey's post hoc test to determine significant differences between the means of the data groups. Comparison of proportions between the three groups was calculated using a $\chi^{2}$ test $(2 \times 3$ table $)$.

To identify which variables were significantly correlated with duration of artificial nutrition, we performed a multiple linear regression using duration of artificial nutrition as a dependent variable. Independent variables were gender, age, diagnosis (dementia $=1$, other $=0$ ), presence or absence of restraint and decubitus, number of incidents of pneumonia, FIM motor scores, FIM cognitive scores, MMSE scores, and methods of artificial nutrition. In a multiple regression analysis, three dummy variables were used instead of 'methods of artificial nutrition' (nominal scale). One dummy variable consisted of PEG = 1 with other $=0$; the other two consisted of NG tube $=1$ with other $=0$ and TPN $=1$ with other $=0$. Subsequently, forward stepwise linear regression models (entrance criterion $p=0.05$, exit $p=0.10$ ) determined if disparate predictors accounted for unique additive variance in the duration of artificial nutrition. A value of $\mathrm{p}<0.05$ was accepted as significant.

\section{Statement of Ethics}

This study adhered to the 1975 Helsinki Declaration of Human Rights. The study protocol with a list of the attending psychiatric hospitals was approved by the Internal Ethical Committee of Okayama University Graduate School of Medicine, Dentistry and Pharmaceutical Sciences.

\section{Results}

\section{Demographic Characteristics}

A total of 168 patients ( 114 women and 54 men, $89.8 \%$ of 187 patients) received artificial nutrition without oral intake. The mean age of the patients was $78.5 \pm 11.1$ years, and the mean duration of artificial nutrition was $30.6 \pm 31.9$ months (table 1). Sixty-six patients (39.3\% of 168 patients) had been receiving artificial nutrition for more than 2 years and 27 patients $(16.1 \%)$ for more than 5 years.

Clinical diagnoses are shown in table 1. Patients with probable AD $(n=71)$ formed the largest group, schizophrenia patients $(n=33)$ the second, and those with $\operatorname{VaD}(n=23)$ the third. Among 71 AD patients, 26 (36.6\%) had been receiving artificial nutrition for more than 2 years and 7 patients $(9.9 \%)$ for more than 5 years. As for the methods of artificial nutrition, 90 patients were receiving it by PEG tube (53.6\%), 63 patients by NG tube (37.5\%), and 15 patients by TPN (8.9\%). Most patients were not under any physical restraint ( $\mathrm{n}=148,88.1 \%)$. Pressure ulcers were found in 22 patients (13.1\%), and pneumonia in the previous year was recorded for 75 patients $(44.6 \%)$.

The distribution of FIM scores is shown in table 2. Twenty-eight patients had the lowest score (13 points) on the FIM motor domain, and more than two thirds of patients ( $n=124)$ scored 14 . About $70 \%$ of the patients $(n=120)$ had the lowest score ( 5 points) on the FIM cognitive domain. On the FIM total score, 25 patients scored 18 (lowest score) and 93 patients (55.4\%) scored 19. The mean MMSE score of 168 patients was $2.0 \pm 5.0$ points, and more than two thirds $(\mathrm{n}=129)$ scored 0 . 


\begin{tabular}{l|l}
\hline DOI: 10.1159/000448242 & $\begin{array}{l}\text { @ 2016 The Author(s). Published by S. Karger AG, Basel } \\
\text { www.karger.com/dee }\end{array}$ \\
\hline
\end{tabular}

Abe et al.: Long-Term Survival of Patients Receiving Artificial Nutrition in Japanese Psychiatric Hospitals

Table 1. Age, diagnosis, duration of artificial nutrition, and pneumonia $(\mathrm{n}=168)$

\begin{tabular}{|c|c|c|}
\hline Characteristics & $\mathrm{n}$ & $\%$ \\
\hline \multicolumn{3}{|l|}{ Age } \\
\hline$\leq 49$ years & 2 & 1.2 \\
\hline $50-59$ years & 6 & 3.6 \\
\hline $60-69$ years & 28 & 16.7 \\
\hline $70-79$ years & 42 & 25.0 \\
\hline $80-89$ years & 64 & 38.0 \\
\hline$\geq 90$ years & 26 & 15.5 \\
\hline \multicolumn{3}{|l|}{ Diagnosis } \\
\hline Probable AD & 71 & 42.2 \\
\hline Schizophrenia & 33 & 19.6 \\
\hline $\mathrm{VaD}$ & 23 & 13.7 \\
\hline DLB & 9 & 5.4 \\
\hline Suffocation accidents & 9 & 5.4 \\
\hline Others & 23 & 13.7 \\
\hline \multicolumn{3}{|l|}{ Duration } \\
\hline$\leq 12$ months & 58 & 34.5 \\
\hline 13-24 months & 44 & 26.2 \\
\hline $25-36$ months & 19 & 11.3 \\
\hline $37-48$ months & 12 & 7.1 \\
\hline 49-60 months & 8 & 4.8 \\
\hline$\geq 61$ months & 27 & 16.1 \\
\hline \multicolumn{3}{|l|}{ Pneumonia incidence } \\
\hline 0 & 93 & 55.3 \\
\hline 1 & 36 & 21.4 \\
\hline 2 & 21 & 12.5 \\
\hline 3 & 6 & 3.6 \\
\hline 4 & 6 & 3.6 \\
\hline $5-6$ & 6 & 3.6 \\
\hline
\end{tabular}

Table 2. Patients' FIM and MMSE scores $(n=168)$

\begin{tabular}{|c|c|c|}
\hline Characteristics & $\mathrm{n}$ & $\%$ \\
\hline \multicolumn{3}{|c|}{ Motor scores of FIM (13-91) } \\
\hline 13 & 28 & 16.7 \\
\hline $14-19$ & 137 & 81.5 \\
\hline $20-26$ & 1 & 0.6 \\
\hline $27-39$ & 0 & 0 \\
\hline$\geq 40$ & 2 & 1.2 \\
\hline \multicolumn{3}{|c|}{ Cognitive scores of FIM (5-35) } \\
\hline 5 & 120 & 71.4 \\
\hline $6-7$ & 17 & 10.1 \\
\hline $8-10$ & 17 & 10.1 \\
\hline $11-15$ & 7 & 4.2 \\
\hline$\geq 16$ & 7 & 4.2 \\
\hline \multicolumn{3}{|c|}{ Total scores of FIM (18-126) } \\
\hline 18 & 25 & 14.9 \\
\hline $19-27$ & 134 & 79.7 \\
\hline $28-36$ & 5 & 3.0 \\
\hline $37-54$ & 2 & 1.2 \\
\hline$\geq 55$ & 2 & 1.2 \\
\hline \multicolumn{3}{|c|}{ MMSE score $(0-30)$} \\
\hline 0 & 129 & 76.8 \\
\hline $1-5$ & 16 & 9.5 \\
\hline $6-10$ & 11 & 6.5 \\
\hline $11-15$ & 7 & 3.6 \\
\hline $16-30$ & 5 & 3.6 \\
\hline
\end{tabular}


Abe et al.: Long-Term Survival of Patients Receiving Artificial Nutrition in Japanese Psychiatric Hospitals

Table 3. Comparison of patients with a different duration of artificial nutrition

\begin{tabular}{|c|c|c|c|c|c|}
\hline & \multicolumn{3}{|c|}{ Duration of artificial nutrition } & \multirow[t]{2}{*}{$\mathrm{F}$} & \multirow[t]{2}{*}{$\mathrm{p}$} \\
\hline & $\begin{array}{l}\text { short } \\
\text { ( } \leq 12 \text { months })\end{array}$ & $\begin{array}{l}\text { middle } \\
(13-36 \\
\text { months })\end{array}$ & $\begin{array}{l}\text { long } \\
(\geq 37 \text { months })\end{array}$ & & \\
\hline Patients, $\mathrm{n}$ & 58 & 63 & 47 & & \\
\hline Mean age \pm SD, years & $78.8 \pm 10.9$ & $78.1 \pm 10.3$ & $78.7 \pm 12.5$ & 0.085 & 0.919 \\
\hline Mean duration $\pm \mathrm{SD}$, months & $6.0 \pm 3.3$ & $21.7 \pm 6.3$ & $72.9 \pm 30.6$ & 221.926 & $<0.001$ \\
\hline Mean MMSE \pm SD & $2.9 \pm 6.1$ & $1.9 \pm 4.4$ & $0.8 \pm 2.7$ & 2.598 & 0.077 \\
\hline Mean FIM motor scores \pm SD & $14.4 \pm 3.7$ & $15.0 \pm 6.1$ & $13.8 \pm 0.4$ & 0.936 & 0.394 \\
\hline Mean FIM cognitive scores \pm SD & $7.1 \pm 5.2$ & $6.4 \pm 3.3$ & $5.8 \pm 1.9$ & 1.408 & 0.248 \\
\hline \multirow[t]{2}{*}{ Mean FIM total scores \pm SD } & $21.5 \pm 7.9$ & $21.4 \pm 8.2$ & $19.6 \pm 2.0$ & 1.137 & 0.323 \\
\hline & & & & $\chi^{2}$ & $\mathrm{p}$ \\
\hline Men/women & $21 / 37$ & $20 / 43$ & $13 / 34$ & 0.877 & 0.645 \\
\hline Dementia/others & $43 / 15$ & $43 / 20$ & $27 / 20$ & 3.330 & 0.189 \\
\hline PEG/NG tube/TPN & $29 / 20 / 9$ & $23 / 35 / 5$ & $38 / 8 / 1$ & 26.289 & $<0.001$ \\
\hline Pneumonia (+/-) & $37 / 21$ & $25 / 38$ & $13 / 34$ & 14.720 & 0.001 \\
\hline Restraint $(+/-)$ & $9 / 49$ & $10 / 53$ & $1 / 46$ & 5.952 & 0.051 \\
\hline Decubitus (+/-) & $12 / 46$ & $6 / 57$ & $4 / 43$ & 4.514 & 0.105 \\
\hline
\end{tabular}

$\mathrm{SD}=$ Standard deviation

\section{Comparison between Short, Medium, and Long Duration of Artificial Nutrition and}

Factors Related to Long Duration of Artificial Nutrition

Comparisons between patients with short, medium, and long duration of artificial nutrition are shown in table 3. The proportion of the three methods of artificial nutrition was significantly different between the three groups. Pneumonia in the previous year was more frequent in patients with a short duration of artificial nutrition. The mean MMSE scores and the percentage of physical restraints in the three groups showed close-to-significant differences (table 3).

Multiple logistic regression analysis showed that the duration of artificial nutrition was predicted by the use of PEG tube, diagnosis, MMSE score, and decubitus according to the following formula $\left(\mathrm{R}^{2}=0.172\right)$ (table 4$)$ : duration of artificial nutrition (months) $=16.373$ $($ PEG tube $=1)-16.976($ dementia $=1)-1.278($ MMSE score $)-14.600($ decubitus $=1)+$ 37.619 .

\section{Discussion}

This is the first study that evaluated both the cognition and functional ability of many patients receiving continuous artificial nutrition, as well as pneumonia, decubitus, and use of restraint [13]. Strikingly, in this study, most cases did not show the lowest score on the FIM motor domain. In the urination item of the FIM motor domain, only patients with a bladder catheter were scored 1 (the lowest score), and patients without a bladder catheter were scored 2 or higher [18]. We found that most patients (more than $80 \%$ ) receiving artificial nutrition lived without a bladder catheter. Meanwhile, in the FIM cognitive domain and MMSE, most patients (70-80\%) received the lowest score (5 points on the FIM cognitive domain or 0 points on the MMSE). 
Table 4. Stepwise multiple regression analysis for duration of artificial nutrition

\begin{tabular}{lrlrrr}
\hline Variable & \multicolumn{1}{l}{ B } & SE & \multicolumn{1}{l}{$\beta$} & t value & p value \\
\hline Constant & 37.619 & 5.055 & & 7.443 & $<0.001$ \\
Stomach tube & 16.373 & 4.563 & 0.256 & 3.589 & $<0.001$ \\
Dementia & -16.976 & 4.901 & -0.250 & -3.464 & 0.001 \\
MMSE & -1.278 & 0.482 & -0.191 & -2.652 & 0.009 \\
Decubitus & -14.600 & 6.773 & -0.155 & -2.156 & 0.033 \\
\hline
\end{tabular}

Stomach tube = Stomach tube (1) or not (0); dementia = dementia (1) or not (0); decubitus = ( $)$ indicates $1,(-)$ indicates 0 .

There have been three studies comparing survival time of patients with PEG and NG feeding [20-22]. Two studies reported a longer survival of patients with PEG than of those with an NG tube [21, 22]. Moreover, Kumagai et al. [22] showed that patients receiving PEG feeding suffered less frequently from aspiration pneumonia than those with an NG tube. Meanwhile, Fay et al. [20] found no significant differences in survival times between patients receiving PEG feeding and those with an NG tube. In this study, we found a significant relationship between PEG use and longer survival of patients. Of course, it is possible that clinicians tend to adopt PEG for patients whom they expect to survive longer. Therefore, we cannot determine the cause-result relationship of PEG use with longer survival by regression analysis or a simple comparison study.

The prognosis of dementia patients with artificial nutrition has been controversial. It has been reported that dementia is a risk factor for shorter survival after PEG surgery [23, 24]. However, in many recent reports, patients with dementia lived as long as those without dementia after PEG insertion [9-12]. In this study, dementia and cognitive test score are related to a shorter duration of artificial nutrition. Needless to say, the clinical characteristics of study samples affect the results greatly. We suppose that the difference in the results arises from the study population. In most previous studies, survival time of dementia patients was compared to that of patients with physical disease [9-12]. However, in this study, the survival duration of dementia patients was compared to that of patients with mental diseases. In this study, we found that dementia patients survived a shorter time than those with other diagnoses, which mainly consisted of psychiatric diseases. In the future, whether patients with mental diseases under artificial nutrition survive much longer than those with physical diseases under artificial nutrition should be clarified.

In this study, the functional state (FIM motor score) was not associated with the duration of artificial nutrition. On FIM motor scores, 28 patients (16.7\%) scored 13 (lowest score), and 124 patients $(73.7 \%)$ scored 14 . Only $9.6 \%$ of the patients scored 15 or more. A so-called floor effect might obscure the effect of the functional state on survival. Of course, cognitive state is closely correlated with functional state in the severest stage of dementia. In this study, MMSE scores were associated with the duration of artificial nutrition. The patients with a longer duration of artificial nutrition showed lower MMSE scores. It is unlikely that patients with lower MMSE scores at the start of artificial nutrition live longer than those with high MMSE scores. Therefore, MMSE scores of patients with a longer duration of artificial nutrition decrease gradually in the course of artificial nutrition.

Serum hypoalbuminemia was reported to be a risk factor for survival in patients with PEG in many studies [3, 9-11,25]. Regretfully, serum albumin was not evaluated in this study. However, hypoalbuminemia is reported to be a very important risk factor for decubitus in severe dementia [26]. Thus, decubitus in this study might be an index of poor nutrition. Our results are in line with those of Shah et al. [27]. 
There are several limitations to this study. First, it is a cross-sectional study, so prognostic factors such as survival time cannot be calculated. Second, in this study, only patients in psychiatric hospitals were included, and patients in nursing homes and general hospitals were not. Therefore, we cannot avoid a selection bias. However, this is the first study that identified the factors related to longer survival among inpatients, including those with mental disorders, with various methods of artificial nutrition.

\section{Acknowledgements}

We sincerely thank Ms. Yifei Tang and Ms. Sachiko Nagayama for their skillful assistance. This work was supported by grants from the Japanese Ministry of Education, Culture, Sports, Science and Technology $(24591713,16$ K10251) and the Zikei Institute of Psychiatry.

\section{References}

$>1$ Candy B, Sampson EL, Jones L: Enteral tube feeding in older people with advanced dementia: findings from a Cochrane systematic review. Int J Palliat Nurs 2009;15:396-404.

$\checkmark 2$ Jaul E, Singer P, Calderon-Margalit R: Tube feeding in the demented elderly with severe disabilities. Isr Med Assoc J 2006;8:870-874.

-3 Suzuki Y, Tamez S, Murakami A, Taira A, Mizuhara A, Horiuchi A, Mihara C, Ako E, Muramatsu H, Okano H, Suenaga H, Jomoto K, Kobayashi J, Takifuji K, Akiyama K, Tahara K, Onishi K, Shimazaki M, Matsumoto M, Ijima M, Murakami M, Nakahori M, Kudo M, Maruyama M, Takahashi M, Washizawa N, Onozawa S, Goshi S, Yamashita S, Ono S, Imazato S, Nishiwaki S, Kitahara S, Endo T, Iiri T, Nagahama T, Hikichi T, Mikami T, Yamamoto T, Ogawa T, Ogawa T, Ohta T, Matsumoto T, Kura T, Kikuchi T, Iwase T, Tsuji T, Nishiguchi Y, Urashima M: Survival of geriatric patients after percutaneous endoscopic gastrostomy in Japan. World J Gastroenterol 2010;16:5084-5091.

4 Kosaka Y, Yamaya M, Nakajoh K, Matsui T, Yanai M, Sasaki H: Prognosis of elderly patients with dysphagia in Japan. Gerontology 2000;46:111-112.

5 Finucane TE, Christmas C, Travis K: Tube feeding in patients with advanced dementia: a review of the evidence. JAMA 1999;282:1365-1370.

6 Garrow D, Pride P, Moran W, Zapka J, Amella E, Delegge M: Feeding alternatives in patients with dementia: examining the evidence. Clin Gastroenterol Hepatol 2007;5:1372-1378.

7 Teno JM, Gozalo PL, Mitchell SL, Kuo S, Rhodes RL, Bynum JP, Mor V: Does feeding tube insertion and its timing improve survival? J Am Geriatr Soc 2012;60:1918-1921.

8 Rudberg MA, Egleston BL, Grant MD, Brody JA: Effectiveness of feeding tubes in nursing home residents with swallowing disorders. JPEN J Parenter Enteral Nutr 2000;24:97-102.

$>9$ Higaki F, Yokota 0, Ohishi M: Factors predictive of survival after percutaneous endoscopic gastrostomy in the elderly: is dementia really a risk factor? Am J Gastroenterol 2008;103:1011-1016.

10 Gaines DI, Durkalski V, Patel A, DeLegge MH: Dementia and cognitive impairment are not associated with earlier mortality after percutaneous endoscopic gastrostomy. JPEN J Parenter Enteral Nutr 2009;33:62-66.

11 Tominaga N, Shimoda R, Iwakiri R, Tsuruoka N, Sakata Y, Hara H, Hayashi S, Morita S, Hamasaki Y, Matsushima T, Miyazaki K, Node K, Fujimoto K: Low serum albumin level is risk factor for patients with percutaneous endoscopic gastrostomy. Intern Med 2010;49:2283-2288.

12 Ashikawa K, Miyazaki M, Otsubo T: Survival after percutaneous endoscopic gastrostomy in elderly patients: prognosis for patients older than 85 years, cases of cerebral infarction and dementia. J St Marianna Univ 2011; 2:79-87.

13 Hirao A, Abe K, Takayama K, Kondo K, Yokota O, Sato Y, Norikiyo T, Sato S, Nakashima T, Hayashi H, Nakata K, Asaba H, Tanaka K, Tanaka R, Morisada Y, Itakura H, Honda H, Okabe N, Oshima E, Terada S: Heterogeneity of patients receiving artificial nutrition in Japanese psychiatric hospitals: a cross-sectional study. Psychogeriatrics 2016, Epub ahead of print.

14 McKhann GM, Knopman DS, Chertkow H, Hyman BT, Jack CR Jr, Kawas CH, Klunk WE, Koroshetz WJ, Manly JJ, Mayeux R, Mohs RC, Morris JC, Rossor MN, Scheltens P, Carrillo MC, Thies B, Weintraub S, Phelps CH: The diagnosis of dementia due to Alzheimer's disease: recommendations from the National Institute on AgingAlzheimer's Association workgroups on diagnostic guidelines for Alzheimer's disease. Alzheimers Dement 2011;7:263-269. 
Abe et al.: Long-Term Survival of Patients Receiving Artificial Nutrition in Japanese Psychiatric Hospitals

15 Gorelick PB, Scuteri A, Black SE, Decarli C, Greenberg SM, Iadecola C, Launer LJ, Laurent S, Lopez OL, Nyenhuis D, Petersen RC, Schneider JA, Tzourio C, Arnett DK, Bennett DA, Chui HC, Higashida RT, Lindquist R, Nilsson PM, Roman GC, Sellke FW, Seshadri S; American Heart Association Stroke Council, Council on Epidemiology and Prevention, Council on Cardiovascular Nursing, Council on Cardiovascular Radiology and Intervention, and Council on Cardiovascular Surgery and Anesthesia: Vascular contributions to cognitive impairment and dementia: a statement for healthcare professionals from the American Heart Association/American Stroke Association. Stroke 2011;42:2672-2713.

16 McKeith IG, Dickson DW, Lowe J, Emre M, O’Brien JT, Feldman H, Cummings J, Duda JE, Lippa C, Perry EK, Aarsland D, Arai H, Ballard CG, Boeve B, Burn DJ, Costa D, Del Ser T, Dubois B, Galasko D, Gauthier S, Goetz CG, Gomez-Tortosa E, Halliday G, Hansen LA, Hardy J, Iwatsubo T, Kalaria RN, Kaufer D, Kenny RA, Korczyn A, Kosaka K, Lee VM, Lees A, Litvan I, Londos E, Lopez OL, Minoshima S, Mizuno Y, Molina JA, Mukaetova-Ladinska EB, Pasquier F, Perry RH, SchulzJB, Trojanowski JQ, Yamada M; Consortium on DLB: Diagnosis and management of dementia with Lewy bodies: third report of the DLB Consortium. Neurology 2005;65:1863-1872.

-17 Rascovsky K, Hodges JR, Knopman D, Mendez MF, Kramer JH, Neuhaus J, van Swieten JC, Seelaar H, Dopper EG, Onyike CU, Hillis AE, Josephs KA, Boeve BF, Kertesz A, Seeley WW, Rankin KP, Johnson JK, Gorno-Tempini ML, Rosen H, Prioleau-Latham CE, Lee A, Kipps CM, Lillo P, Piguet O, Rohrer JD, Rossor MN, Warren JD, Fox NC, Galasko D, Salmon DP, Black SE, Mesulam M, Weintraub S, Dickerson BC, Diehl-Schmid J, Pasquier F, Deramecourt V, Lebert F, Pijnenburg Y, Chow TW, Manes F, Grafman J, Cappa SF, Freedman M, Grossman M, Miller BL: Sensitivity of revised diagnostic criteria for the behavioural variant of frontotemporal dementia. Brain 2011; 134:2456-2477.

18 Keith RA, Granger CV, Hamilton BB, Sherwin FS: The functional independence measure: a new tool for rehabilitation. Adv Clin Rehabil 1987;1:6-18.

19 Folstein MF, Folstein SE, McHugh PR: 'Mini-mental state'. A practical method for grading the cognitive state of patients for the clinician. J Psychiatr Res 1975;12:189-198.

20 Fay DE, Poplausky M, Gruber M, Lance P: Long-term enteral feeding: a retrospective comparison of delivery via percutaneous endoscopic gastrostomy and nasoenteric tubes. Am J Gastroenterol 1991;86:1604-1609.

-21 Dwolatzky T, Berezovski S, Friedmann R, Paz J, Clarfield AM, Stessman J, Hamburger R, Jaul E, Friedlander Y, Rosin A, Sonnenblick M: A prospective comparison of the use of nasogastric and percutaneous endoscopic gastrostomy tubes for long-term enteral feeding in older people. Clin Nutr 2001;20:535-540.

22 Kumagai R, Kubokura M, Sano A, Shinomiya M, Ohta S, Ishibiki Y, Narumi K, Aiba M, Ichimiya Y: Clinical evaluation of percutaneous endoscopic gastrostomy tube feeding in Japanese patients with dementia. Psychiatry Clin Neurosci 2012;66:418-422.

23 Mitchell SL, Kiely DK, Lipsitz LA: The risk factors and impact on survival of feeding tube placement in nursing home residents with severe cognitive impairment. Arch Intern Med 1997;157:327-332.

24 Sanders DS, Carter MJ, D’Silva J, James G, Bolton RP, Bardhan KD: Survival analysis in percutaneous endoscopic gastrostomy feeding: a worse outcome in patients with dementia. Am J Gastroenterol 2000;95:1472-1475.

25 Kaw M, Sekas G: Long-term follow-up of consequences of percutaneous endoscopic gastrostomy (PEG) tubes in nursing home patients. Dig Dis Sci 1994;39:738-743.

26 Pivi GA, Bertolucci PH, Schultz RR: Nutrition in severe dementia. Curr Gerontol Geriatr Res 2012;2012: 983056.

27 Shah PM, Sen S, Perlmuter LC, Feller A: Survival after percutaneous endoscopic gastrostomy: the role of dementia. J Nutr Health Aging 2005;9:255-259. 